\title{
Sensitivity of BRCA1/2 mutation testing in 466 breast/ ovarian cancer families
}

\author{
D G R Evans, M Bulman, K Young, D Gokhale, F Lalloo
}

J Med Genet 2003;40:e107 (http://www.jmedgenet.com/cgi/content/full/40/9/e107)

A ffected individuals from 431 families gave blood for mutational analysis in BRCAI and BRCA2 mainly to develop genetic tests for their family. Individuals were eligible if there was at least a $50 \%$ chance of a gene predisposing to breast cancer (not necessarily BRCA1/2) in their family. Assessment was made using the Cancer and Steroid Hormone (CASH) dataset and the Claus curves. ${ }^{12} \mathrm{~A}$ minimal requirement was two close relatives with breast cancer before the age of 50 years, but combinations of male and female breast cancer, and breast and ovarian cancer were particularly identified. An exception to this were two research projects where population based cases of breast cancer before the age of 31 years ${ }^{3}$ and sporadic breast cancer before the age of 36 years $^{4}$ were screened for both genes. Male breast cancer (MBC) families presenting to the clinic with at least one MBC before the age of 60 years or at any age if female breast cancer had occurred were screened for BRCA2.5

Initial screening for mutations involved a whole gene assessment using single strand conformational polymorphism (SSCP) analysis and protein truncation testing (PTT) of exon 11 in each gene. All mutations were confirmed, in both orientations, by direct fluorescent sequencing of the appropriate exon. We excluded one exon 13 duplication and two exonic deletions detected on screening 95 BRCAl negative breast/ovarian families. A further two exon 13 duplications in five subsequent BRCAI negative breast/ovary families originating from east of the Pennines were also excluded. Of the non large-scale rearrangement mutations, 26/78 (33\%) were detected outside the commonly screened regions of BRCAl (exons $2,11,20$ ) in the UK (table 1). Similarly 15/50 (30\%) BRCA2 mutations were detected outside exons 10 and 11 .

In an attempt to assess the sensitivity of our techniques, we studied the outcome of testing in families with two or more confirmed ovarian cancers, which also had a total of at least four breast/ovarian cancers (breast cancer before the age of 60 years) and male breast cancer families with a similar four or more breast/ovarian cancers in total. Of breast/ovarian families fulfilling the above criteria, 25/38 (66\%) had pathogenic BRCAl mutations (five had BRCA2 mutations and one had a BRCAl deletion) and 9/14 (64\%) male breast cancer families had pathogenic BRCA2 mutations. ${ }^{5}$ These results would suggest high sensitivity for the techniques, particularly for BRCA2. From Breast Cancer Linkage Consortium data, $90 \%$ of such breast-ovarian families were linked to BRCAl, and $76 \%$ of male breast cancer families were linked to $B R C A 2 .{ }^{6}$ This would suggest sensitivity of close to $85 \%$ for $B R C A 2$ and $73 \%$ for BRCA1. However, previous attempts to validate SSCP have shown that only $65-72 \%$ of BRCAl mutations are correctly ascribed by SSCP. ${ }^{78}$ PTT detected all 15 deleterious mutations in one study, but SSCP only detected $10 .{ }^{8}$ Nevertheless sensitivity is not just dependent on the proportion of different mutations detected, but on the frequency of each in a particular population. Taking all these factors into account we have estimated that our whole gene testing technique (without testing for large deletions or

\section{Key points}

- Partial or targeted mutation screening of BRCA1/2 in non-founder populations of limited value.

- Whole gene screening adding a deletion strategy such as multiplex ligation dependent probe amplification will give good negative predictive value particularly in breast only families where risks of ovarian cancer can be substantially downgraded.

- The $546 \rightarrow$ T mutation in exon 7 BRCA 1 is missed by most non-sequencing techniques and appears to be a common UK mutation, which has spread to North America.

- Samples from affected family members from 431 nonJewish families with a history of breast/ovarian cancer, which had been obtained from a consultee in northwest England, were screened for the presence of BRCA 1 mutations. We also screened 284 such families for BRCA2 mutations.

- In total, 466 families were tested for mutations in one or other gene and 318 for both genes. Both BRCA1 and BRCA2 were screened by whole gene screening techniques; 83 (19\%) and 50 (18\%) pathogenic mutations were identified in BRCAl and BRCA2, respectively.

duplications) would have a sensitivity of at least 66\% (see table 2 ), and that about $6 \%(4 / 66)$ of our breast/ovarian families have deletions or large-scale rearrangements.

The proportion of breast/ovarian cancers attributable to $B R C A 1$ or BRCA2 depends on the ethnic origin of families. Many countries or ethnic groups have particular founder mutations that are not seen in other populations. In countries with a small founder population, very few mutations may account for the vast majority of breast cancer families. The Ashkenazi Jewish population have three founder mutations, 185delAG and 5382insC in BRCA1, and 6174delT in BRCA2, which are found in over $2 \%$ of the this population. At least two studies have shown that one of the three mutations is present in the majority $(59 \%-80 \%)$ of high risk families ${ }^{9}{ }^{10}$, and all three account for nearly all of the involvement of these genes in families. Another country with a small number of mutations is Iceland, where one mutation, BRCA2 995del5, accounts for most familial breast cancer. ${ }^{11}$ Populations that are more outbred, such as the UK, have larger numbers of mutations, and founder mutations occur at lower frequencies. Even the exon 13 duplication, a known UK founder ${ }^{12}$, is

Abbreviations: PIT, protein truncation test(ing); SSCP, single strand conformational polymorphism 


\begin{tabular}{|c|c|c|c|c|c|}
\hline Gene & Exon & Mutation & Codon & Effect & $\begin{array}{l}\text { Number of } \\
\text { families }\end{array}$ \\
\hline BRCAl & 5 & 278delC & 68 & $168 x$ & 1 \\
\hline BRCAl & 5 & $331+1 G \rightarrow C$ & NA & Splice site & 1 \\
\hline BRCAl & 5 & $331-11 \mathrm{~T} \rightarrow \mathrm{G}$ & NA & Splice site & 2 \\
\hline BRCAl & IVS6 & 421-2delA & NA & Splice site & 1 \\
\hline BRCAl & 7 & $546 \mathrm{G} \rightarrow \mathrm{T}$ & 143 & Stopl 43 & 6 \\
\hline BRCAl & 8 & $666+1 G \rightarrow T$ & NA & Splice site & 1 \\
\hline BRCAl & IVS10 & $790-1 \mathrm{G} \rightarrow \mathrm{A}$ & NA & Splice site & 1 \\
\hline BRCAl & 13 & $4446 C \rightarrow T$ & 1443 & R1 443X & 1 \\
\hline BRCA1 & 13 & $\begin{array}{l}\text { Exon } 13 \\
\text { duplication }\end{array}$ & NA & NA & 3 \\
\hline BRCAI & 15 & $\begin{array}{l}4604-2 \\
A \rightarrow G\end{array}$ & NA & Splice site & 1 \\
\hline BRCAl & 15 & $4744 \mathrm{delCT}$ & 1542 & Stop 1572 & 2 \\
\hline BRCAl & 16 & 5061 delA & 1648 & Stopl 657 & 1 \\
\hline BRCAI & 18 & $\begin{array}{l}5271+4 \\
A \rightarrow G\end{array}$ & NA & Splice site & 1 \\
\hline BRCA1 & 21 & 5427delG & 1792 & Stopl792 & 1 \\
\hline BRCA1 & 22 & $5464 \mathrm{G} \rightarrow \mathrm{A}$ & 1782 & W1782X & 1 \\
\hline BRCA1 & 24 & $5622 \mathrm{C} \rightarrow \mathrm{T}$ & 1835 & R1835X & 2 \\
\hline BRCA1 & $\begin{array}{l}\text { Deletion } \\
\text { exons } \\
3-15\end{array}$ & NA & NA & NA & 1 \\
\hline BRCAl & $\begin{array}{l}\text { Deletion } \\
\text { exons } \\
14-20\end{array}$ & NA & NA & NA & 1 \\
\hline BRCA2 & 2 & 253delC & 9 & STOP24 & 1 \\
\hline BRCA2 & & 767 insAT & 180 & Stopl85 & 1 \\
\hline BRCA2 & 7 & 800delAT & 266 & Stop204 & 1 \\
\hline BRCA2 & IVS7 & IVS7+2 T $\rightarrow G$ & NA & Splice site & 2 \\
\hline BRCA2 & 8 & $860 \mathrm{G} \rightarrow \mathrm{A}$ & NA & Splice site & 1 \\
\hline BRCA2 & 9 & 983delACAG & 252 & Stop275 & 2 \\
\hline BRCA2 & 16 & $\begin{array}{l}\text { 7990delATA } \\
\text { insTT }\end{array}$ & 2588 & Stop 2647 & 1 \\
\hline BRCA2 & 17 & $\begin{array}{l}8205-1 \\
G \rightarrow C\end{array}$ & NA & Splice site & 1 \\
\hline BRCA2 & 18 & $8525 \mathrm{delC}$ & 2766 & Stop 2776 & 2 \\
\hline BRCA2 & 22 & $9132 \mathrm{del} C$ & 2968 & Stop2975 & 1 \\
\hline BRCA2 & 22 & $9179 \mathrm{C} \rightarrow \mathrm{G}$ & 2984 & Stop2984 & 1 \\
\hline BRCA2 & 23 & 9318 insA & 3030 & Stop 3047 & 1 \\
\hline
\end{tabular}

relatively rare outside Yorkshire and Trent (east of the Pennines) as demonstrated by our low frequency of 1/95 (1\%) in BRCAl negative breast/ovary families. Nevertheless, many laboratories in the UK have tried to develop a targeted approach to screening, concentrating on the large exons (exon 11 in both genes and 10 in BRCA2) and the smaller exons commonly reported to be involved, such as 2 and 20 in $B R C A 1$. This cuts down the number of PCR assays using PTT to as few as five for BRCAl and four for BRCA2. However, failure to use another technique such as SSCP at the beginning and end of the large exons would potentially miss our two most common mutations, 2157 delG in BRCA2 (nine families) and 4184 del TTAC in BRCAl ( 12 families). These mutations are not reliably detected by PTT as they are at the extreme ends of exon 11 in both genes. ${ }^{13}$ This would therefore add four PCR assays to BRCA2 testing and two to BRCA1. Even with these additional assays, sensitivity for the whole gene is boosted from only around $33 \%$ to $44-46 \%$ (table 2 ). The utility of a negative test in this situation is negligible. However, once sensitivity rises beyond $66 \%$ the chances of a $B R C A 1 / 2$ mutation being present in the family at least halves using Bayes' theorum. Thus in a family with 4-5 breast cancers before the age of 60 years (no ovarian or male breast cancer), which has around a $33 \%$ chance of being due to $B R C A 1 / 2,{ }^{6}$ a negative test would substantially reduce the estimate of ovarian cancer risk for family members. Taking an average risk for BRCAl/2 of $30 \%$ lifetime chance for ovarian cancer, the risk estimate for an affected woman with breast cancer could be as much as an extra $10 \%$ prior to
Table 2 Sensitivity of mutation screening techniques for $B R C A 1 / 2$

\begin{tabular}{|c|c|c|}
\hline \multirow[b]{2}{*}{ Technique } & \multicolumn{2}{|c|}{ Proportion of mutations detected } \\
\hline & BRCAI & BRCA2 \\
\hline $\begin{array}{l}\text { 1(a) PTT large exons+2, } \\
20 \text { BRCA } 1 \text { (A) - } \\
\text { Assumes } 66 \% \text { sensitivity } \\
\text { for whole gene approach }\end{array}$ & $40 / 78(51 \%)$ & $26 / 50(52 \%)$ \\
\hline 1(b) Add deletion test & $39 \%$ for whole gene & $?$ \\
\hline (MLPA/MAPH) & $33 \%$ for whole gene & $33 \%$ for whole gene \\
\hline $\begin{array}{l}2 \text { (a) A+SSCP ends of } \\
\text { large exons. } \\
\text { Sensitivity for whole gene } \\
\text { approach } 66 \%\end{array}$ & $52 / 78(67 \%)$ & $35 / 50(70 \%)$ \\
\hline 2(b) Add deletion test & $\begin{array}{l}50 \% \text { for whole gene } \\
44 \% \text { for whole gene }\end{array}$ & ? $46 \%$ for whole gene \\
\hline $\begin{array}{l}3 \text { (a) SSCP+PTT for whole } \\
\text { gene }\end{array}$ & $65-73 \%$ & $65-85 \%$ \\
\hline 3(b) Add deletion test & $71-79 \%$ & $?$ \\
\hline $\begin{array}{l}\text { 4(a) Sequencing whole } \\
\text { gene or similar very high } \\
\text { sensitivity strategy leg } \\
\text { DHPLC) }\end{array}$ & $85 \%$ & $85-90 \%$ \\
\hline 4(b) Add deletion test & $91 \%$ & \\
\hline
\end{tabular}

A-PTT large exons+2/20 BRCA1.

testing. However, with a negative whole gene screen this extra ovarian cancer risk will fall to below $5 \%$, and $2.5 \%$ for at-risk unaffected relatives.

Adding an exon deletion/duplication strategy such as multiplex ligation dependent probe amplification (MLPA) ${ }^{14}$ would add an extra $6 \%$ sensitivity in our sample (table 1 ), but in other populations such as the Netherlands could account for up to $27 \%$ or more of BRCAl pathogenic mutations. ${ }^{15}$ As this is a single assay, it or a similar test should probably now be added to all BRCA screening strategies. As can be seen from table 2 even direct sequencing plus a technique such as MLPA does not reach $100 \%$ sensitivity. This is because mutations buried in the intron that affect splicing, or effects outside the gene that affect RNA transcription would not be detected. Indeed, chromosome translocations not affecting an exon would also be undetected. Nevertheless many pathogenic mutations might be inappropriately labelled "undetected", as many missense changes of uncertain pathogenic significance remain unclassified. Improvements in classifying these variants should boost mutation detection sensitivity further. ${ }^{16}$

Our results would also suggest that for the UK at least exon 11 in BRCAI does not account for more mutations than would be predicted from its size alone. Only 48/83 (58\%) pathogenic BRCAl mutations were detected in exon 11, which is equivalent to its contribution of $60 \%$ to the coding sequence. Similarly only $5 / 34(14 \%)$ of the non-Jewish non-exon 11 BRCAl mutations were in exons 2 and 20. Indeed exons 5 and 7 contribute more mutations individually than either exons 2 or 20. The finding of six exon $7546 \mathrm{G} \rightarrow \mathrm{T}$ mutations is of particular significance. We were initially unable to cover the whole of this exon by SSCP due to the large number of repeat sequences in the intron. It is our understanding from other groups that virtually no laboratory has been able to obtain workable non-sequencing results for exon 7. Eventually we sequenced exon 7 in 30 breast/ovarian families previously negative on BRCAl testing. Three families tested positive for the $546 \mathrm{G} \rightarrow$ T mutation. We have now tested 201/354 families testing negative for other BRCAl pathogenic changes and identified six of these mutations. Although the most likely families have been tested it is possible that at least a further two mutations would be identified on testing the remainder. It is likely this mutation is more than just a local founder 
mutation as it has been recorded 30 times on the BIC website $^{17}$ by Myriad Genetics and only twice by other laboratories. Given the frequency of this mutation in our northwest population and Myriad it would suggest that many laboratories are missing the mutation even if they are screening exon 7 unless they are using sequencing techniques. It would also suggest that this mutation should be incorporated into even a partial gene screen in the UK.

\section{Authors' affiliations}

D G R Evans, M Bulman, K Young, D Gokhale, F Lalloo, Academic Unit of Medical Genetics, Regional Genetics Service, and National Genetics Reference Laboratory, St Mary's Hospital, Manchester M13 OJH, UK

Correspondence to: Professor D G R Evans, Consultant Clinical Geneticist, Academic Unit of Medical Genetics and Regional Genetic Service, St. Mary's Hospital, Hathersage Road, Manchester M13 OJH, UK; gareth.evans@cmmc.nhs.uk

\section{REFERENCES}

1 Claus EB, Risch N, Thompson WD. Autosomal dominant inheritance of early onset breast cancer. Cancer 1994;73:643-51.

2 Evans DGR, Lalloo F. Risk assessment and management of high risk familial breast cancer. J Med Genet 2002;39:865-71.

3 Lalloo F, Varley J, Ellis D, Moran A, O'Dair L, Pharoah P, Evans DGR, the Early Onset Breast Cancer Study Group. Prediction of pathogenic mutations in patients with early onset breast cancer by family history. Lancet 2003;361:1101-2.

4 Ellis D, Greenman J, Hodgson S, et al. Low prevalence of germline BRCA mutations in early onset sporadic breast cancer. J Med Genet 2000;37:792-4.
5 Evans DGR, Bulman $M$, Young $K$, et al. High detection rate for BRCA2 mutations in male breast cancer families from North West England. Familial Cancer 2002;3:131-3.

6 Ford D, Easton M, Stratton S, et al. Genetic heterogeneity and penetrance analysis of the BRCA1 and BRCA2 genes in breast cancer families. Am J Hum Genet 1998;62:676-89.

7 Eng C, Brody LC, Wagner TM, et al. Steering Committee of the Breast Cancer Information Core (BIC) Consortium. Interpreting epidemiological research: blinded comparison of methods used to estimate the prevalence of inherited mutations in BRCA1. J Med Genet 2000;38:824-33.

8 Andrulis IL, Anton-Culver H, Beck J, et al. Cooperative Family Registry for Breast Cancer studies. Comparison of DNA- and RNA-based methods for detection of truncating BRCA1 mutations. Hum Mutat 2002 Jul;20(1):65-73.

9 Levy-Lahad E, Catane R, Eisenberg S, et al. Founder BRCA1 and BRCA2 mutations in Ashkenazi Jews in Israel: frequency and differential penetrance in ovarian cancer and in breast-ovarian cancer families. Am J Hum Genet 1997:60(5): 1059-67.

10 Lalloo F, Cochrane S, Bulman B, et al. An evaluation of common breast cancer mutations within a population of Ashkenazi Jews. J Med Genet 1998;35:10-12.

11 Johannesdottir G, Gudmundsson J, Bergthorsson JT, et al. High prevalence of the 999del5 mutation in icelandic breast and ovarian cancer patients. Cancer Res 1996;56(16):3663-5.

12 The BRCA1 Exon 13 Duplication Screening Group. The exon 13 duplication in the BRCA1 gene is a founder mutation present in geographically diverse populations. Am J Hum Genet 2000;77:207-12.

13 Davies JF, Redmond EK, Cox MC, et al. 2157delG: a frequent mutation in BRCA2 missed by PTT. J Med Genet 2000;37:e42.

14 Schouten JP, McElgunn CJ, Waaijer R, et al. Relative quantification of 40 nucleic acid sequences by multiplex ligation-dependent probe amplification. Nucleic Acids Res 2002;30(12):e57.

15 Hogervorst FB, Nederlof PM, Gille JJ, et al. Large genomic deletions and duplications in the BRCA1 gene identified by a novel quantitative method. Cancer Res 2003;63(7): 1449-53.

16 Fleming MA, Potter JD, Ramirez CJ, et al. Understanding missense mutations in the BRCA 1 gene: an evolutionary approach. Proc Natl Acad Sci USA 2003;100(3): 1151-6.

17 National Human Genome Research Institute: Breast Cancer Information Core. An open access on-line breast cancer mutation data base. http:// www.nhgri.nih.gov/Intramural_research/Lab_transfer/Bic/Access. 